\title{
Genetic Diversity Analysis of Kilakarsal Sheep by Microsatellite Markers
}

\author{
T. Ravimurugan* \\ Veterinary University Training and Research Centre, Nagercoil - 629 601, Tamil Nadu, India \\ *Corresponding author
}

\section{A B S T R A C T}

Keywords

Characterization, Kilakarsal, Sheep, Microsatellites.

Article Info

Accepted:

04 July 2017

Available Online:

10 September 2017
Kilakarsal sheep population variability and structure was investigated genetically utilizing FAO recommended 25 microsatellite markers. Estimates of genetic variability such as effective number of alleles and gene diversities revealed substantial genetic variation detected by microsatellite markers. A total of 241 alleles were detected and the actual number of observable alleles ranged from five (BM6526) to a maximum of 16 (MAF70). The mean number of alleles (allelic diversity) was 9.64. The effective number of alleles which is lower than the observed number of alleles, was between 2.279 (OarCP20) and 8.510 (MAF70) with a mean of 4.786 alleles. The average observed heterozygosity $\left(\mathrm{H}_{\mathrm{o}}\right)$ and expected heterozygosity $\left(\mathrm{H}_{\mathrm{e}}\right)$ were 0.690 and 0.782 respectively. However, the study evidenced a significant departure from Hardy-Weinberg equilibrium in 13 loci. Such lack seems to be caused by a rather high level of inbreeding $\left(F_{\text {IS }}=0.097\right)$.

\section{Introduction}

Kilakarsal sheep, one among of the registered breeds is distributed in the southern districts of Tamil Nadu. They are medium sized with compact body conformation and reared for meat purpose. The distinct breed characters include dark tan coat dorsally and black colour ventrally in the belly and inner side of legs. Rams have well developed twisted horns while ewes are polled.

The present study is carried out to estimate the inbreeding level in the field animals thus how various forces of genetic change are modifying the foundation genetic structure of the population. This will provide genetic information to be used for conservation and improvement of this population.

\section{Materials and Methods}

Blood samples of fifty genetically unrelated sheep were collected from breeding tract of Kilakarsal sheep to make them representative of the population. Genomic DNA was isolated as per the method described by Miller et al., (1988) with minor modifications. The isolated DNA samples were quantified by agarose gel electrophoresis and visualized by UV spectrophotometer. After checking the quality and quantity, DNA was diluted to a final concentration of 50ng/ $\mu \mathrm{l}$ using Tris EDTA buffer and stored at $-20^{\circ} \mathrm{C}$.

A battery of 25 microsatellite markers was selected based on the guidelines of ISAG (International Society of Animal Genetics) and FAO's DADIS (Domestic Animal 
Diversity Information System). Polymerase Chain Reaction (PCR) was carried out on about 50ng genomic DNA in a $15 \mu$ l reaction volume using Mastercycler ep gradients (Eppendorf, Germany). The reaction mixture consisted of one $\mu 1$ template DNA, $0.5 \mu \mathrm{l}$ of primers (forward and reverse), $7.5 \mu \mathrm{l}$ of $2 \mathrm{X}$ PCR mastermix and $5.5 \mu \mathrm{l}$ of triple distilled water.

The PCR protocol used with initial denaturation of $94^{\circ} \mathrm{C}$ for $5 \mathrm{~min}, 3$ cycles of $94^{\circ} \mathrm{C}$ for 45 seconds, annealing for 35 seconds (temperature ranged from $51^{\circ} \mathrm{C}$ to $61.5^{\circ} \mathrm{C}$ ), extension of 35 seconds at $72^{\circ} \mathrm{C}, 35$ cycles, a final extension at $72^{\circ} \mathrm{C}$ for $10 \mathrm{~min}$. The genotypes were scored by the ABI Genetic Analyzer and GeneMapper ${ }^{\mathrm{Tm}}$ version 4.0 (Applied Bio-systems, Germany). Of the 25 microsatellite loci, all loci amplified successfully and produced definite banding patterns.

The original microsatellite allelic data is available from the first author upon request. For 25 microsatellite loci, genetic variation of the breed and breed structure was elucidated using allele frequencies, observed and effective number of alleles, observed and expected heterozygosities and within breed heterozygosity deficit (estimated using Wrights fixation index). All the estimates were derived using POPGENE version 3.1 program (Yeh et al., 1999). Allelic frequencies were utilized for the calculation of the Polymorphism Information Content (PIC) values (Botstein et al., 1980).

\section{Results and Discussion}

The allelic diversity and genetic variation are presented in table 1. A total of 241 alleles were detected. The number of alleles observed across the microsatellite loci varied from five (BM6526) to 16 (MAF70). The observed number of alleles across the loci was more than the effective number of alleles $(4.78 \pm 1.72)$ as expected. Total number of alleles observed in this study was higher than the values reported for five other Tamil Nadu sheep, Nilagiri 125 (Girish et al., 2007), Vembur 147 (Pramod et al., 2009), Madras Red 98 (Selvam et al., 2009), Coimbatore 143 (Kumarasamy et al., 2009) and Tiruchy Black 195 alleles (Kavitha, 2010) as well as this is higher than 190 alleles for the same breed as reported by Radha et al., (2011).

However, direct comparisons with the earlier characterized breeds cannot be justified, as the method of genotyping in the earlier studies was manual (by silver staining) and a slightly different set of markers was used.

The allelic diversity is a reasonable parameter of genetic variation which revealed that Kilakarsal harboured a good amount $(9.64 \pm$ 2.82) of genetic variation as this breed possessed more than four alleles (Li et al., 2002). The allelic diversity in this study were observed to be higher than 7.6 reported for the same breed (Radha et al., loc.cit) probably because of genotyping accomplishment under this study by automated DNA sequencer rather than by silver staining technique and also different set of markers used.

The average expected genetic diversity within the population ranged from 0.5613 (OarCP20) to 0.8825 (MAF70). The average genetic variation $\left(\mathrm{H}_{0}=0.762 \pm 0.088\right)$ in Kilakarsal sheep was higher than that reported for the genetic variation in Nellore and Pattanam $\left(\mathrm{H}_{\mathrm{o}}=0.658\right.$ and 0.666$)$ by Ramachandran (2012). In assessing diversity estimates from different studies, it should be mentioned that the values are not directly comparable as different microsatellite sets were used by different workers. These values have only suggestive indication of diversity in the populations. Expected heterozygosity is considered to be a better estimator of the genetic variability in a population. 
Table.1 Number of alleles, observed and expected heterozygosities, polymorphism information content, Shannon's information index,

FIS, Hardy-Weinberg equilibrium (HWE) and Nei’s genetic distance values for Kilakarsal sheep

\begin{tabular}{|c|c|c|c|c|c|c|c|c|c|c|}
\hline \multirow{2}{*}{ Microsatellite Marker } & \multirow{2}{*}{$\mathbf{n}_{\mathbf{a}}$} & \multirow{2}{*}{$\mathbf{n}_{\mathbf{e}}$} & \multirow{2}{*}{$\mathbf{H}_{\mathbf{o}}$} & \multirow{2}{*}{$\mathbf{H}_{\mathrm{e}}$} & \multirow{2}{*}{ PIC } & \multirow{2}{*}{$\mathbf{I}$} & \multirow{2}{*}{$F_{\text {IS }}$} & \multicolumn{2}{|c|}{ HWE } & \multirow{2}{*}{$\mathbf{D}$} \\
\hline & & & & & & & & $\chi^{2}$ & d.f & \\
\hline BM757 & 12 & 5.7143 & 0.7000 & 0.8462 & 0.797 & 2.0399 & 0.1515 & $53.08^{\mathrm{NS}}$ & 66 & 0.8250 \\
\hline BM827 & 6 & 3.1375 & 0.6000 & 0.6987 & 0.6293 & 1.3393 & 0.1195 & $10.10^{\mathrm{NS}}$ & 15 & 0.6813 \\
\hline BM1329 & 9 & 5.4422 & 0.9500 & 0.8372 & 0.7911 & 1.8518 & -0.1639 & $49.60^{\mathrm{NS}}$ & 36 & 0.8163 \\
\hline BM6506 & 11 & 5.1613 & 1.0000 & 0.8269 & 0.7696 & 1.9124 & -0.2403 & $55.05^{\mathrm{NS}}$ & 5 & 0.8063 \\
\hline BM6526 & 5 & 3.1250 & 0.5500 & 0.6974 & 0.6223 & 1.2760 & 0.1912 & $9.53^{\mathrm{NS}}$ & 10 & 0.6800 \\
\hline BM8125 & 8 & 3.9604 & 0.4500 & 0.7667 & 0.7118 & 1.6375 & 0.3980 & $73.82 * *$ & 28 & 0.7475 \\
\hline CSSM31 & 13 & 5.4795 & 0.9500 & 0.8385 & 0.6969 & 2.0575 & -0.1621 & $115.11 * *$ & 78 & 0.8175 \\
\hline ILSTO33 & 6 & 3.2000 & 0.6000 & 0.7051 & 0.6449 & 1.3964 & 0.1273 & $19.07^{\mathrm{NS}}$ & 15 & 0.6875 \\
\hline MAF65 & 9 & 2.9851 & 0.6000 & 0.6821 & 0.6445 & 1.5598 & 0.0977 & $80.23 * *$ & 36 & 0.6650 \\
\hline MAF70 & 16 & 8.5106 & 0.8000 & 0.9051 & 0.5119 & 2.4353 & 0.0935 & $108.70^{\mathrm{NS}}$ & 120 & 0.8825 \\
\hline MAF209 & 8 & 3.0303 & 0.6500 & 0.6872 & 0.6387 & 1.4882 & 0.0299 & $43.76^{*}$ & 28 & 0.6700 \\
\hline MCM527 & 9 & 4.3478 & 0.5000 & 0.7897 & 0.7442 & 1.7546 & 0.3506 & $67.54 * *$ & 36 & 0.7700 \\
\hline OarCP20 & 6 & 2.2792 & 0.7000 & 0.5756 & 0.4892 & 1.0524 & -0.2472 & $42.52 * *$ & 15 & 0.5613 \\
\hline OarFCB20 & 11 & 4.3243 & 0.5500 & 0.7885 & 0.7467 & 1.8614 & 0.2846 & $101.92 * *$ & 55 & 0.7688 \\
\hline OarCP34 & 11 & 6.6116 & 0.9500 & 0.8705 & 0.8314 & 2.1337 & -0.1193 & $116.24 * *$ & 55 & 0.8488 \\
\hline OarFCB48 & 12 & 8.0808 & 0.9500 & 0.8987 & 0.8267 & 2.2563 & -0.0842 & $55.79^{\mathrm{NS}}$ & 66 & 0.8225 \\
\hline OarFCB128 & 7 & 3.8095 & 0.4500 & 0.7514 & 0.7002 & 1.5675 & 0.3898 & $35.45^{*}$ & 36 & 0.7375 \\
\hline OarFCB304 & 6 & 2.3324 & 0.6500 & 0,5859 & 0.5209 & 1.1371 & -0.0379 & $3.17^{\mathrm{NS}}$ & 21 & 0.5713 \\
\hline OarAE129 & 12 & 4.5455 & 0.3500 & 0.8000 & 0.7312 & 1.9734 & 0.5513 & $140.39 * *$ & 66 & 0.7800 \\
\hline OarJMP29 & 14 & 7.0796 & 0.7500 & 0.8805 & 0.6741 & 2.2871 & 0.1266 & $80.10^{\mathrm{NS}}$ & 91 & 0.8588 \\
\hline OarHH35 & 8 & 4.8780 & 0.4500 & 0.8154 & 0.7652 & 1.7364 & 0.4340 & $71.07 * *$ & 28 & 0.7950 \\
\hline OarHH47 & 10 & 4.3478 & 0.7000 & 0.7897 & 0.7504 & 1.8563 & 0.0909 & $61.21^{\mathrm{NS}}$ & 45 & 0.7700 \\
\hline OarVH72 & 9 & 5.5556 & 0.8000 & 0.8410 & 0.7979 & 1.8964 & 0.0244 & $60.95 * *$ & 36 & 0.8200 \\
\hline SRCRSP5 & 11 & 4.3716 & 0.7500 & 0.7910 & 0.6176 & 1.8910 & 0.0276 & $121.75^{* *}$ & 55 & 0.7712 \\
\hline SRCRSP9 & 12 & 7.3394 & 0.8500 & 0.8859 & 0.7888 & 2.1792 & 0.0159 & $66.45^{\mathrm{NS}}$ & 66 & 0.8638 \\
\hline Mean & 9.64 & 4.7860 & 0.6900 & 0.7824 & 0.6977 & 1.7831 & 0.0979 & - & - & 0.7628 \\
\hline S D & 2.8267 & 1.7253 & 0.1843 & 0.0903 & 0.09 & 0.3640 & - & - & - & 0.0880 \\
\hline
\end{tabular}

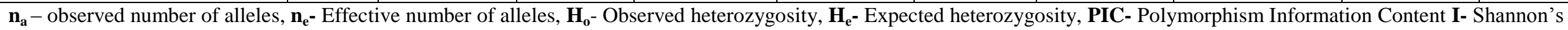

Information Index, $\boldsymbol{F}_{\text {IS }}$ - Within population inbreeding estimate, $\boldsymbol{\chi 2} \mathbf{2}$ - Chi- square value, d.f- Degrees of freedom and $\mathbf{D}-\mathrm{Nei}$ 's genetic distance.

NS-Not Significant *- Significant $* *$ - Highly significant 
The high mean (both observed and expected) values estimated in the present study showed that Kilakarsal sheep possess a substantial level of genetic diversity that might be used in planning breeding strategies.

The within breed inbreeding estimate $\left(F_{\text {IS }}\right)$ reported in most of the Tamil Nadu sheep breeds indicated various levels of inbreeding as 0.004 in Mecheri sheep (Prema et al., 2008), 0.295 in Vembur breed (Pramod et al., loc.cit) and 0.147 in Kilakarsal sheep (Radha et al., loc.cit). Heterozygote deficiency analysis revealed significant deviation from Hardy-Weinberg equilibrium $(\mathrm{P}<0.01)$ at several loci. The exact basis of this departure is difficult to explain, however, the presence of low frequency of null alleles segregating at the loci. There are other more potent forces than null alleles that cause heterozygote deficiency e.g. within population inbreeding, mainly due to use of limited number of sires. The Shannon information index $(1.783 \pm 0.364)$ and polymorphic information content $(0.697 \pm$ 0.090) showed that most of the loci were highly informative indicating polymorphism across the loci, thus suggesting the suitability of these markers for genetic diversity studies in other sheep breeds of India.

Kilakarsal sheep had substantial genetic variation as indicated by high allele and genetic diversity. The breed lost its genetic identity due to excessive gene flow resulted from the invading effect by rams of Chevaadu breed of sheep. The study, however, also suggests that such an uncontrolled mating is avoided for maintaining pure germplasm of Kilakarsal, which possessed unique alleles.

\section{References}

Barker, J.S.F., 1994. In 'A global protocol for determining genetic distance among domestic livestock breeds' Proceedings of the world congress held at University of Guelph, pp. 501.

Botstein, D., White, R.L., Skolnick, M. and Davis, R.W. 1980. Construction of a genetic linkage map in man using restriction fragment length polymorphisms. Am. J. Hum. Genet, 32: 314-331.

Girish, H., Sivaselvam, S.N., Karthickeyan, S.M.K. and Saravanan, R. 2007. Molecular characterisation of Nilagiri sheep (Ovis aries) of south India based on microsatellites. Asian Aust. J. Anim., 20: 633-637.

Kavitha, S.T., 2010. Molecular characterization of Tiruchy Black Sheep. M.V.Sc. Thesis. Tamil Nadu Veterinary and Animal Sciences University, Chennai.

Kumarasamy, P., Prema, S., Ganapathi, P., Karthickeyan, S.M.K. and Kanakaraj, P. (2009). Molecular characterization of Coimbatore breed of sheep (Ovis aries) in south India. Icfai. Univ. J. Genet. Evol, 2: 55-56.

Li, M.H., Jhao, S.H.E., Bian, C., Wang, H.S., Wei, H., Liu, B., Yu, M., Fan, B., Chen, C.L., Zhu, M.J., Li, S.J., Xiong, T.A and Li, K. 2002. Genetic relationship among twelve Chineese indigenous goat populations based on microsatellite analysis. Genet. Selection Evol, 34: 729744.

Miller, S.A., Dykes, D.D. and Polesky, H.F. 1988. A simple salting out procedure for extracting DNA from human nucleated cells. Nucleic Acids. Res., 16: 1215.

Pramod, S., Kumarasamy, P., Rosalyn Mary Chandra, A., Sridevi, P. and Rahumathulla, P.S. 2009. Molecular characterization of Vembur sheep (Ovis aries) of south India based on microsatellites. Indian J. Sci. Technol., 2: 55-58.

Prema, S., Sivaselvam, S.N. and Karthickeyan, S.M.K. 2008. Evaluation 
of genetic diversity in Mecheri sheep (Ovis aries) of Tamil Nadu using microsatellite markers. Indian $J$. Biotechnol., 7: 401-403.

Radha, P., Sivaselvam, S.N., Kumarasamy, P. and Kumanan, K. 2011. Genetic diversity and bottleneck analysis of Kilakarsal sheep by microsatellite markers. Indian J. Biotechnol., 10: 5255.

Ramachandran, A., 2012. M.V.Sc. Thesis. Tamil Nadu Veterinary and Animal Sciences University, India.
Selvam, R., Rahumathulla, P. S., Sivaselvam, S. N., Karthickeyan, S. M. K. and Rajendran, R. 2009. Molecular genetic characterization of Madras Red sheep in Tamil Nadu, India using microsatellite markers. Livest. Res. Rural Dev., 21: 50 .

Yeh, F.C., Boyle, T., Rongcai, Y., Ye, Z. and Xian, J.M. 1999. Popgene, Version 1.31. A Microsoft Windows Based Freeware for Population Genetic Analysis. University of Alberta, Edmonton.

\section{How to cite this article:}

Ravimurugan, T. 2017. Genetic Diversity Analysis of Kilakarsal Sheep by Microsatellite Markers. Int.J.Curr.Microbiol.App.Sci. 6(9): 573-577. doi: https://doi.org/10.20546/ijcmas.2017.609.069 